\title{
Antimicrobial Activity and Chemical Constituents of the Extract from Jatropha curcas Fruit
}

\author{
KANDA SAOSOONG and CHALERM RUANGVIRIYACHAI* \\ Department of Chemistry,Faculty of Science, Khon Kaen University, \\ Khon Kaen 40002, Thailand. \\ *Corresponding author E-mail: chal_ru@ @ku.ac.th
}

http://dx.doi.org/10.13005/ojc/320242

(Received: February 27, 2016; Accepted: March 25, 2016)

ABSTRACT

\begin{abstract}
The antimicrobial activity and chemical constituents of the methanolic extract from J. curcas fruit were evaluated in this study. The crude extract was achieved by extraction with $60 \%(\mathrm{v} / \mathrm{v})$ methanol. It showed the potencies of antimicrobial activity against $P$. putida, $P$. syringae pv. sesami, $X$. campestris, $X$. campestris pv. glycines, $X$. campestris pv. vesicatoria and $R$. solanacearum with the presence of inhibition zone in the range of $8.0 \pm 0.0$ to $13.7 \pm 0.6 \mathrm{~mm}$ and MIC value at $214.29 \pm 0.00$ $\mu \mathrm{g} / \mathrm{mL}$. Furthermore, flavone compound can be proposed by the analysis of gas chromatographymass spectrometry (GC-MS). According to the group of flavonoid compounds have strong bioactive properties; the results suggested that $J$. curcas fruit has highly potential as effective natural bioactive sources.
\end{abstract}

Keywords: Jatropha curcas fruit, Antimicrobial activity, Disc diffusion method, Broth micro-well dilution method, GC-MS analysis.

\section{INTRODUCTION}

Polyphenolic compounds such as flavonoids, coumaric acids and tannins possess many biological activities which are attributed to their antimicrobial activity ${ }^{1,2}$. These compounds also demonstrate antiviral, anti-inflammatory and anticancer properties ${ }^{3}$. Especially, flavonoids are well known as polyphenolic substances with strong bioactive activity which obtained from many types of medicinal plants ${ }^{4}$. However, in currently the synthetic bioactive compounds such as butylatedhydroxyanisole(BHA), butylatedhy- droxytoluene (BHT) and tert-butylhydroquinone are usually used in industrial process ${ }^{3,5,6}$. The synthetic antimicrobial chemicals are also used in the treatment of infectious diseases. However, these compounds have been considered the toxic and carcinogenic effect which can cause serious disease to human body ${ }^{7}$. Accordingly, the importance of searching for natural antimicrobial compounds for replacement the using of synthetic compounds has increased significantly in the present.

One of medicinal plants which are interesting for the natural antimicrobial compounds 
elucidation is Jatropha curcas (J. curcas). It is a multipurpose plant in Euphorbiaceae family which has a lot of economic significance, especially for biodiesel production source and also its medicinal values $^{8,9}$. Numerous parts of $J$. curcas plant have been studied about phytochemical compound identification for searching new natural bioactive compounds in previously reported ${ }^{8,10}$. The parts of $J$. curcas plant such as roots, stems, barks, leaves, seeds, which can be used for various purposes including medicinal value ${ }^{11,12}$. Accordingly, the studies about finding natural bioactive compounds from other parts of $J$. curcas plant are interesting. This study focuses on the antimicrobial activity of chemical constituents from whole fruit of J. curcas, which has no report available on the study of the entire J. curcas fruit in previous research. The J. curcas green fruits were selected to study in this work, as shown in Figure 1.

Therefore, the aims of the present study were to evaluate the antimicrobial activity of methanolic extract from J. curcas fruit. Additionally, gas chromatography-mass spectrometry (GC-MS) was used to identify the chemical constituents in methanolic extract of $J$. curcas fruit. The achieved information would indicate the possible of the $J$. curcas fruit extract as a new source of natural bioactive compounds. Especially, there are plentiful J. curcas plants in Thailand. In order to add value of the local plants besides the biodiesel production, the study is important.

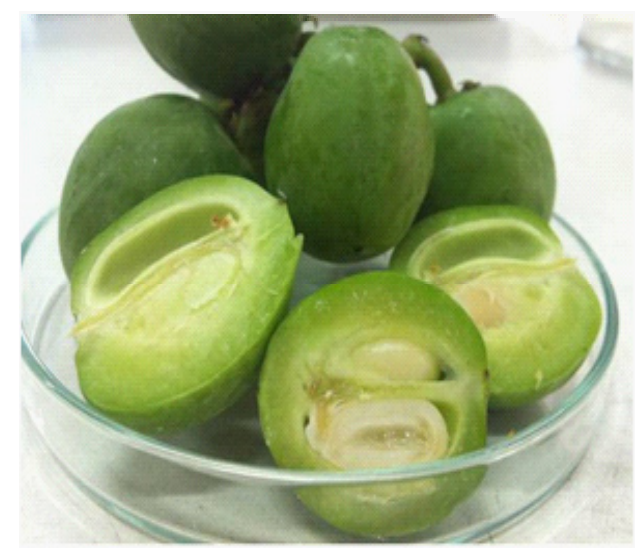

Fig. 1: The Jatropha curcas fruits

\section{MATERIALS AND METHODS}

J. curcas fruit was kindly supported by Khon Kaen Field Crops Research Center (KKFCRC)Khon Kaen Province, Thailand. The analytical grade of organic solvent including methanol,ethanol, hexane, dichloromethane, chloroform and ethyl acetate were purchased from Carlo Erba (Italy). The analytical grade of dimethyl sulfoxide (DMSO) was obtained from $\mathrm{RCl}$ Labscan (Thailand). The culture media including Nutrient agar (NA), Nutrient broth (NB), Agar powder, Mueller-Hinton agar (MHA) and Mueller-Hinton broth (MHB) were purchased from Himedia (India). Gentamicin sulfate salt hydrate was also obtained from Sigma-Aldrich (Switzerland). A Supelclean ${ }^{\mathrm{TM}}$ LC-Si SPE cartridge $(6 \mathrm{~mL}, 500 \mathrm{mg})$ was purchased from Supelco (USA).

\section{Bacterial strains}

The microorganisms for antimicrobial activity evaluation including seven plant pathogenic bacteria, there are P. putida, P. syringae pv. sesami, $X$. campestris, $X$. campestris pv. glycines, $P$. syringae, $X$. campestris pv. vesicatoria and $R$. solanacearum. All microorganisms were obtained from Microbiological Resources Center, Bangkok, Thailand Institute of Science and Technological Research (TISTR), Thailand.

\section{The extraction of $J$. curcas fruit}

The extraction was conducted according to the method of Oskoueian et al., (2011) with slight modification ${ }^{1}$.Briefly, powdered J. curcas sample $(10 \mathrm{~g})$ was extracted three times with $50 \mathrm{~mL}$ of $60 \%$ $(\mathrm{v} / \mathrm{v})$ methanol by shaken with an orbital shaker (Yamato Scientific, Japan) at $150 \mathrm{rpm}$ at ambient temperature $\left(30{ }^{\circ} \mathrm{C}\right)$ for $2 \mathrm{~h}$. The extract was then filtered through a Whatman No. 1 filter paper. Afterward, combined filtrates were evaporated by rotary vacuum evaporation. The obtained crude extracted solution was further fractionated by loading through a Supelclean ${ }^{\mathrm{TM}}$ LC-Si SPE cartridge and eluted with $25 \mathrm{~mL}$ of hexane, dichloromethane, chloroform, ethyl acetate and methanol, respectively. The solvent of each fraction was removed by rotary vacuum evaporation and the obtained remainder defined as $F_{1}, F_{2}, F_{3}, F_{4}$ and $F_{5}$, respectively. 


\section{Determination of antimicrobial activity \\ Disc diffusion method}

In order to evaluate the antimicrobial activity of crude methanolic extract from J. curcas fruit, the disc diffusion method was selected according to the reported of Gulluce et al., (2007) with small modification $^{13}$. The seven plant disease bacteria were evaluated. Firstly, each test bacterial strain was grown in nutrient broth (NB) liquid medium at $37^{\circ} \mathrm{C}$ for $24 \mathrm{~h}$. The obtained inoculum was then diluted with sterile water to achieve the optical density $\left(\mathrm{OD}_{600}\right)$ equal to McFarland No. 0.5 (1.5 x 108 CFU/ $\mathrm{mL}$ ). Afterward, $100 \mu \mathrm{L}$ of this bacterial solution was spread on the Mueller-Hinton agar (MHA) in Petri dishes and allowed to dryness. Finally, sterile paper discs with crude methanolic extracts were carefully applied on the surface of the preparing agar plate which containing tests microorganism. Gentamicin was used as positive control and negative control was also set up by the equal quantity of DMSO. These obtained agar plates were then incubated at $37{ }^{\circ} \mathrm{C}$ for $24 \mathrm{~h}$ and the antimicrobial activity was evaluated by measuring the inhibition zone. The experiments were performed in triplicate.

\section{Broth micro-well dilution method}

For evaluate the minimum inhibitory concentration (MIC) value of the extracts the broth micro-well dilution method was performed as the report of Kivrak et al., (2009) ${ }^{14}$. Briefly, the highest concentration of crude methanolic extract $(1000 \mu \mathrm{g} / \mathrm{mL}$ ) was prepared two-fold serial dilutions in Mueller-Hinton Broth (MHB). $75 \mu \mathrm{L}$ of the culture media (Mueller-Hinton Broth) was added into each hole of 96 -well microplates. $100 \mu \mathrm{L}$ of the initially concentration of crude methanolic extract at 1000 $\mathrm{g} / \mu \mathrm{L}$ were added into the first raw of microplate. Afterward, their serial dilutions were prepared by

Table 1: The Antimicrobial Activity of Crude Methanolic Extract From J. curcas Fruit

\begin{tabular}{lcc}
\hline \multirow{2}{*}{ Plant Disease Bacteria } & \multicolumn{2}{c}{ Antimicrobial Activity } \\
& Inhibitionzone $(\mathbf{m m})$ & MIC $(\boldsymbol{\mu g} / \mathbf{m L})$ \\
\hline Pseudomonas putida & $13.7 \pm 0.6$ & $214.29 \pm 0.02$ \\
Pseudomonas syringae pv. sesami & $10.0 \pm 0.0$ & $428.57 \pm 0.04$ \\
Xanthomonas campestris & $8.0 \pm 0.0$ & $214.29 \pm 0.00$ \\
Xanthomonas campestris pv. glycines & $8.3 \pm 0.6$ & $214.29 \pm 0.00$ \\
Pseudomonas syringae & inactive & inactive \\
Xanthomonas campestris pv. vesicatoria & $8.7 \pm 0.6$ & $214.29 \pm 0.02$ \\
Ralstonia solanacearum & $8.3 \pm 0.6$ & $428.47 \pm 0.02$ \\
\hline
\end{tabular}

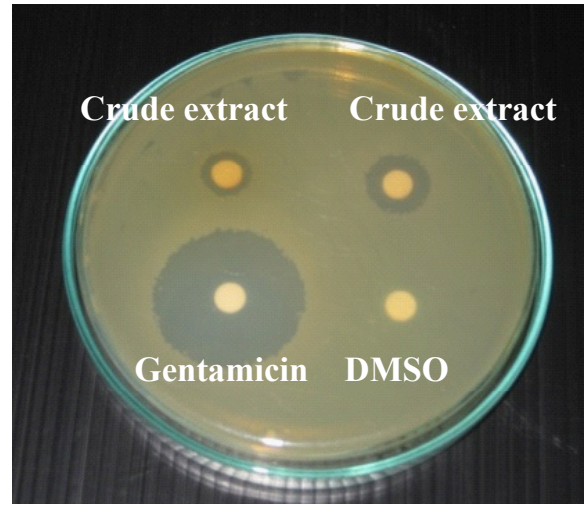

(a)

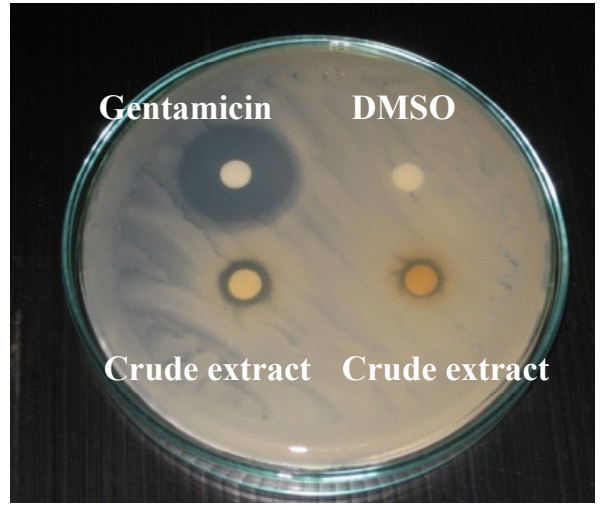

(b)

Fig. 2: Disc diffusion inhibition zone of (a) P.putida, (b) X.campestrispv. glycines 
transferring $100 \mu \mathrm{L}$ of solution into consecutive wells. Each microorganism was grown in nutrient broth (NB) liquid medium by incubation at $37^{\circ} \mathrm{C}$ for $24 \mathrm{hrs}$. The inoculation of bacteria was prepared by dilution with sterile water until the bacterial cell equal to McFarland No. 0.5 ( $\left.1.5 \times 10^{8} \mathrm{CFU} / \mathrm{mL}\right)$. And then, $25 \mu \mathrm{L}$ of the inoculum was added into each raw of microplate. These solutions were mixed and incubated at $37^{\circ} \mathrm{C}$ for $24 \mathrm{~h}$. Finally, the absorbance at $655 \mathrm{~nm}$ was recorded by using a microplate reader. Gentamicin was also used as positive control for antimicrobial activity. The experiments were performed in triplicate.

\section{Identification the chemical constituents of the extracts using GC-MS}

In order to identify the extracted compounds which contain in the extracts, a Thermo Finigan Polaris Q mass spectrometer (USA) coupled to an Agilent trace GC chromatograph were used. The separation of the analytes was performed on a methyl silicone HP-5 MS capillary column (30 m x $0.25 \mathrm{~mm}$ i.d., $0.25 \mu \mathrm{m}$ film thicknesses). Briefly, $1 \mu \mathrm{L}$ of the extracts was injected into the gas chromatograph using splitless mode. The carrier gas was helium with flow rate $1 \mathrm{~mL} \mathrm{~min}^{-1}$. The extracts in methanol were injected at a column oven temperature of $70{ }^{\circ} \mathrm{C}$, in which this temperature was programmed to increase from $70^{\circ} \mathrm{C}-280^{\circ} \mathrm{C}$ at $10^{\circ} \mathrm{C} /$ minutes. The transfer line temperature was at $275^{\circ} \mathrm{C}$ and the ion source temperature maintained at $200{ }^{\circ} \mathrm{C}$. Electron impact (EI) mass spectra $(70 \mathrm{eV})$ of the parent compounds were recorded. A mass range of $\mathrm{m} / \mathrm{z}$ 50-650 was scanned, data attained and processed by using theXcalibur software version 1.3.

\section{Statistical analysis}

Statistical analysis was carried out using Microsoft Corporation Computer Excel Program (USA). All experiments were performed in triplicate. The results were presented as a value \pm standard deviation of mean (SD).

\section{RESULTS AND DISCUSSION}

\section{Antimicrobial activity of the crude methanolic extract}

The activity of crude methanolic extracts from $J$. curcas fruit on seven plant disease bacteria were evaluated by Disc diffusion method and Broth micro-well dilution method. The results showed that the extract indicated the potencies of antimicrobial activity against six plant disease bacteria including $P$. putida, $P$. syringae pv. sesami, $X$. campestris, $X$. campestrispv. glycines, $X$. campestrispv. vescicatoria and $R$. solanacearum as shown in Table 1.This extract exposed antimicrobial activity effect against six plant disease bacteria with inhibition zone in the range of $8.0 \pm 0.0$ to $13.7 \pm 0.6 \mathrm{~mm}$ and moderate antimicrobial activity with MIC value at $214.29 \pm 0.00 \mu \mathrm{g} / \mathrm{mL}$. The instance of antimicrobial activity of this extract against some tests bacterial strain including $P$. putida and $X$. campestris pv. glycines were shown in Fig. 2.

As the results, the crude methanolic extract showed lower antimicrobial activities than of that positive control, gentamicin. It exposed antimicrobial activity effect with varying degrees of growth inhibition zone against the test bacterial strains. For the selected criteria of antimicrobial activity evaluation, the extract with MIC less than75 $\mu \mathrm{g} / \mathrm{mL}$ was considered to have strong antimicrobial activity, MIC $75-150 \mu \mathrm{g} / \mathrm{mL}$, the antimicrobial activity was moderate and MIC more than $250 \mu \mathrm{g} / \mathrm{mL}$ the antimicrobial activity was considered inactive ${ }^{15}$.

Consequently, the crude methanolic extract as this work revealed moderate antimicrobial activity against $P$. putida, $X$. campestris, $X$. campestris pv. glycines, $X$. campestris pv. vesicatoria. The obtained antimicrobial activity may correspond with the bioactive compounds which contained in the medicinal plant such as phenolic and flavonoid compounds as described in previous report ${ }^{16-18}$. For instance, Bounatirou et al., (2007) described that the main components in studied plant extract that showed the antimicrobial activity were terpene phenols ${ }^{19}$. Moreover, as the study of Hamed et al., (2015), two flavonol compounds exhibited significant antimicrobial effect against Candida albicans, Staphylococcus aureus and Escherichia coli bacteria ${ }^{20}$. However, this activity may be due to the content of phorbol ester. In which many of reports described that phorbol ester containing in high quantity in the part of J. curcas seed 5 . According to the obtained antimicrobial activity in this study, the chemical constituent in the crude methanolic extract from $J$. curcas fruit can be served as an effective natural antimicrobial source. 
GC-MS analysis of the extract from $J$. curcas fruit

The crude methanolic extract of $J$. curcas fruit was fractionated by using a Supelclean ${ }^{\mathrm{TM}}$ LCSi SPE cartridge and the fractions specify as $F_{1}$, $F_{2}, F_{3}, F_{4}$ and $F_{5}$ were obtained. The yellow solution of methanolic fraction $\left(F_{5}\right)$ was selected to identify by GC-MS due to the high quantity of this fraction was achieved. The mass spectrum of interested compound $(R T=11.38)$ with the predominant fragment at $\mathrm{m} / \mathrm{z} 223.44$ and $\mathrm{m} / \mathrm{z} 327.35$ was shown in Fig. 3. The type of phenolic compound was tentatively identified on the basis of retention time and mass pattern, as well as comparing into the dada in related literature. However, there is no report available in the literature on the characterization of the methanolic extract from $J$. curcas fruit. The compound may be proposed that this extract contain the component of some flavonoid compound due to the pattern of flavone skeleton was identified. Consequently, it is possible that their antimicrobial activity of this methanolic extract may be due to the containing of the proposed compound, flavone. Importantly, many case of flavonoid compound show strong antimicrobial activity in the literature reported ${ }^{21,22}$.

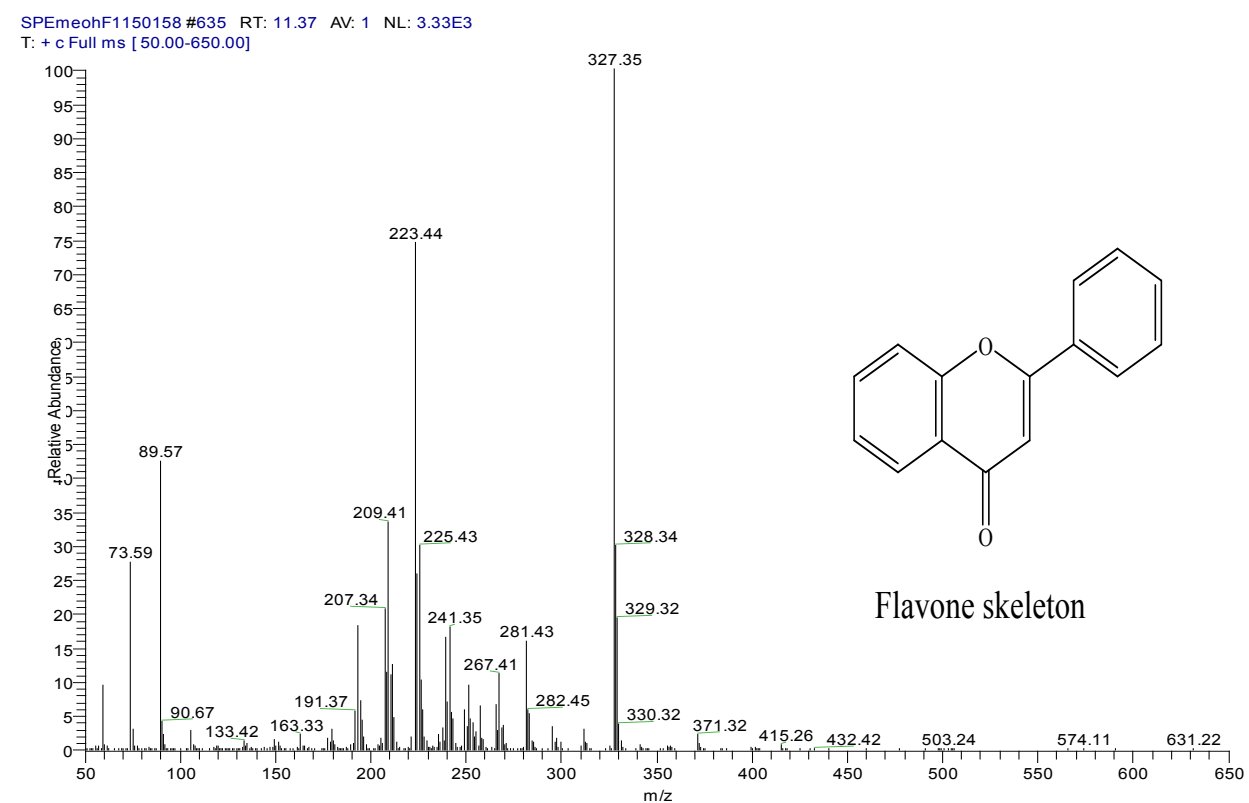

Fig. 3: The mass spectrum of methanolic extract from $\mathrm{J}$. curcas fruit at RT $=11.38$

\section{CONCLUSIONS}

According to many of researches required about management of $J$. curcas as to know more about the utilization of its products. Especially, there are plentiful $J$. curcas plants in Thailand due to the encouragement of $J$. curcas cultivation increase for biodiesel production source over the last several years. Consequently, this research was performed in order to support these purposes by evaluating the utilization of other part of $J$. curcas such as its fruit part. It was found that the of $J$. curcas fruit gave antimicrobial activities against $P$. putida, $P$. syringae pv. sesami, $X$. campestris, $X$. campestris pv. glycines, $X$. campestris pv. vesicatoria, $R$. solanacearum. The chemical constituent analysis by GC-MS technique demonstrated that flavone compound can be proposed. The results confirm that $J$. curcas fruits are the source of some important bioactive compounds which corresponding the antimicrobial properties and may be useful for medicinal application in the future. 


\section{ACKNOWLEDGEMENTS}

Financial support from National Research University Project of Thailand, Office of the Higher Education Commission through the Biofuel Cluster
Khon Kaen University, Thailand is gratefully acknowledged. The authors also thank Department of Chemistry, Faculty of Science, Khon Kaen University for all supportive experiment facilities.

\section{REFERENCES}

1. Oskoueian, E.; Abdullah, N.; Ahmad, S.; Saad, W.Z.; Omar, A.R.; Ho, Y.W. Bioactive compounds and biological activities of Jatrophacurcas L. kernel meal extract.Int. J. Mol. Sci.,2011, 12(9), 5955-5970.

2. Namuli, N.A. Phytochemical compounds and antibacterial activity of Jatropha curcas Linn. extracts. J. Med. Plant Res.,2011, 5(16),39823990.

3. El-Baz, F.K.; Ali, F.F.; El-Rahman, A.A.; Aly, H.F.; Saad, S.A.; Mohamed, A.A. HPLC evaluation of phenolic profile, and antioxidant activity of different extracts of Jatropha curcas leaves. Int. J. Pharm. Sci. Rev. Res., 2014, 29(1), 203-210.

4. Igbinosa, O.O.; Igbinosa, I.H.; Chigor, V.N.; Uzunuigbe, O.E.; Oyedemi, S.O.; Odjadjare, E.E. Polyphenolic contents and antioxidant potential of stem bark extracts from Jatropha curcas (Linn).Int. J. Mol. Sci.,2011, 12, 2958-2971.

5. Tongpoothorn,W.; Chanthai, S.; Sriuttha, M.; Saosoong, K.; Ruangviriyachai, C.Bioactive properties and chemical constituents of methanolic extract and its fractions from Jatropha curcas oil.Ind. Crops. Prod.,2012, 36(1), 437-444.

6. Erkan, N.; Ayranci, G.; Ayranci, E. Antioxidant activities of rosemary (Rosmarinus Officinalis L.) extract, blackseed (Nigella sativa L.) essential oil, carnosic acid, rosmarinic acid and sesamol. Food Chem.,2008, 110(1),7682.

7. Dung, N.T.; Kim, J.M.; Kang, S.C.Chemical composition, antimicrobial and antioxidant activities of the essential oil and the ethanol extract of Cleistocaly xoperculatus (Roxb.) Merr and Perry buds. Food Chem. Toxicol.,2008, 46(12), 3632-3639.

8. Kumar, A.; Sharma, S. An evaluation of multipurpose oil seed crop for industrial uses
(Jatropha curcas L.): A review.Ind. Crops. Prod.,2008, 28(1),1-10.

9. Kamal, A.; Manmohan, S.; Birendra, S. A review on chemical and medicobiological applications of Jatropha curcas. Int. Res. J. Phar.,2011, 2(4), 61-66.

10. Phengnuam, T.; Goroncy, A.K.; Rutherfurd, S.M.; Moughan, P.J.; Suntornsuk, W. DPPH radical scavenging activity of a mixture of fatty acids and peptide-containing compounds in a protein hydrolysate of Jatropha curcas seed cake.J. Agric. Food Chem.,2013, 61(48), 11808-11816.

11. Yao, L.; Han, C.; Chen, G.; Song, X.; Chang, Y.; Zang, W. A new asymmetric diamide from the seed cake of Jatropha curcas L.Fitoterapia,2012, 83(8),1318-1321.

12. Zhang, X.Q.; Li, F.; Zhao,Z.G.; Liu,X.L.; Tang, Y.X.; Wang, M.K. Diterpenoids from the root bark of Jatropha curcas and their cytotoxic activities.Phytochem. Lett.,2012, 5(4),721724.

13. Gulluce, M.; Sahin, F.; Sokmen, M.; Ozer, H.; Sokmen, A. Antimicrobial and antioxidant properties of the essential oils and methanol extract from Mentha longifolia L. ssp. Iongifolia. Food Chem.,2007, 103(4),1449-1456.

14. Kivrak, I.; Duru, M.E.; Öztürk, M.; Mercan, N.; Harmandar, M.; Topçu, G. Antioxidant, anticholinesterase and antimicrobial constituents from the essential oil and ethanol extract of Salvia potentillifolia. Food Chem.,2009, 116(2), 470-479.

15. Scorzoni, L.; Benaducci, T; Almeida, A.M.F.; Silva, D.H.S.; Bolzani, V.S.; Mendes-Giannini, M.J.S. Comparative study of disk diffusion and microdilution methods for evaluation of antifungal activity of natural compounds against medical yeasts Candidaspp and Cryptococcus sp. Rev. Ciênc. Farm. Básica Apl., 2007, 28(1), 25-34. 
16. Erbil, N.; Duzguner, V.; Durmuskahya, C.; Alan, Y. Antimicrobial and antioxidant effects of some Turkish fodder plants belongs to Fabaceae family (Viciavillosa, Trifolium ochroleucum and Onobrychis altissima). Orient. J. Chem.,2015, 31(3), 1263-1268.

17. Rattanakom, S.; Yasurin, P. Chemical profiling of Centella asiatica under different extraction solvents and its antibacterial activity, antioxidant activity. Orient. J. Chem., 2015, 31(4), 2453-2459.

18. Parajuli, R.; Banerjee, J.; Khanal, H. Synthesis of some pyrazolone derivatives and evaluation of its antibacterial and cytotoxic activity. Orient. J. Chem.,2015, 31(4), 2099-2106.

19. Bounatirou, S.; Smiti, S.; Miguel, M.G., Faleiro, L.; Rejeb, M.N.; Neffati, M.Chemical composition, antioxidant and antibacterial activities of the essential oils isolated from
Tunisian Thymus capitatus Hoff. et Link. Food Chem.,2007, 105(1),146-155.

20. Hamed, M.M.; Refahy, L.A.; Abdel-Aziz, M.S. Evaluation of antimicrobial activity of some compounds isolated from Rhamnus cathartica L. Orient. J. Chem., 2015, 31(2), 1133-1140.

21. Gupta, J.; Gupta, A. Isolation and extraction of flavonoid from the leaves of Rauwolfia serpentina and evaluation of DPPHscavenging antioxidant potential. Orient. J. Chem.,2015, 31(SplEdn), 231-235.

22. Plazoniæ, A.; Bucar, F.; Males, A.; Nigoviæ, B.; Kujundziæ, N. Identification and quantification of flavonoids and phenolic acid in Burr Parsley (Caucalis platycarpos L.), using highperformance liquid chromatography with diode array detection and electrospray ionization mass spectrometry. Molecules,2009, 14, 2466-2490. 